\title{
Statistical Characteristics of Subtropical Jet-Stream Features in Terms of MRIR Observations from Nimbus II
}

\author{
Frank L. Martin ${ }^{1}$ and Vincent V. Salomonson \\ Goddard Space Flight Cenler, Greenbell, $M d$.
}

(Manuscript received 23 September 1969, in revised form 19 January 1970)

\section{ABSTRACT}

\begin{abstract}
A sample of 60 individual cases of southwesterly jet-stream maxima located over the continental United States during the Nimbus II period is studied in relation to the MRIR characteristics surrounding the jet. The analysis has been conducted primarily from a statistical point-of-view applied to the equivalent blackbody temperature $\left(T_{B B}\right)$ patterns of channels 1,2 and 4 , and to hypsometric combinations of these $T_{B B}$ values representing layer-mean temperatures. It was found that certain gross features of the fieids of convergence and divergence associated with the moisture distribution in certain quadrants surrounding the jet are consistently indicated in these patterns. A stepwise, multiple regression analysis for specification of the maximum wind speeds gives predictive skill in several channels, particularly in the 5-30 $\mu$ channel, indicating that baroclinic effects can be discerned by MRIR observations applied to suitably stratified data samples.
\end{abstract}

\section{Introduction}

Several useful papers have appeared in the literature (Oliver et al., 1964; Whitney et al., 1966; Johnson, 1966) describing the feasibility of locating jet streams through characteristic cloud features observable in meteorological satellite photographs. The parallel objective of characterizing jet streams, and in particular jet wind speed maxima, in terms of digitized fields of emitted terrestrial radiation detected by the various sensors on meteorological satellites is an equally useful problem and is the objective of this paper.

Beran $e t$ al. (1968) have addressed themselves to the latter problem. They examined the continuity of four independently selected jet-stream case sequences observed over North America during the lifetime of the Nimbus II Medium Resolution Infrared Radiometer (MRIR) data period (15 May-28 July 1966). They concluded that a general pattern of radiometric values, particularly in the 6.4-6.9 $\mu$ spectral region, may "in general be associated with jet streams and upper tropospheric cyclones in both the extratropical and subtropical regions."

In this paper the approach is somewhat more quantitative in that statistical procedures have been employed on a random sample of 60 jet maxima in which the direction of flow was southwesterly. Through the use of a grid system, radiometric values at 13 objectively selected points symmetrically located about each jet maximum were obtained (see Fig. 1). In order to reduce the variation in as many physical variables as possible,

1 This co-author performed his contribution during his tenure as a National Academy of Sciences-National Research Council Senior Postdoctoral Resident Research Associate with the National Aeronautics and Space Administration. He has since returned to the Navy Postgraduate School at Monterey, Calif. case stratification to southwesterly subtropical jets occurring over the United States was set forth as a requirement. While this represents a limitation upon the generality of the approach, insight into the more general problem of jet analysis through radiometric parameters results. The statistical approach adopted here was designed to achieve two general objectives:

1) The determination of spatial consistencies in the medium resolution infrared radiation (MRIR) fields relative to jet stream maxima.

2) The assessment of the usefulness of stepwise regression analysis for selecting MRIR variables that

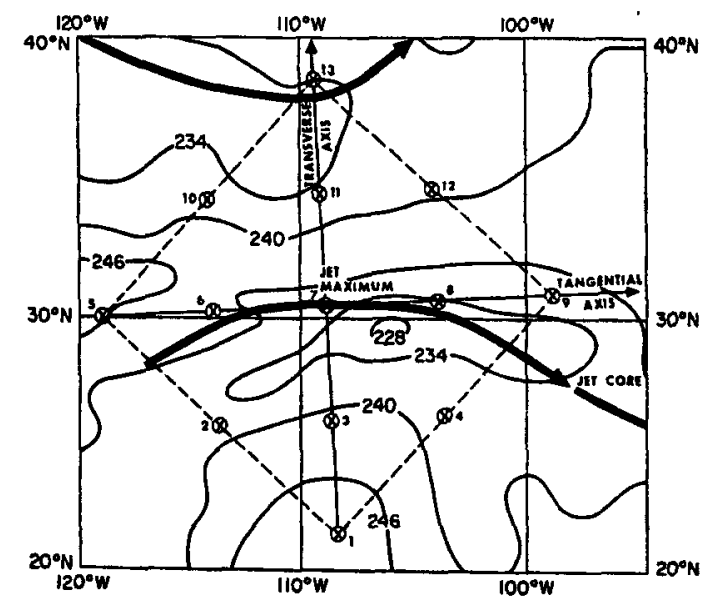

Frc. 1. The jet-maximum case of 1200 GMT 5 June 1966. The grid overlay used for MRIR map sampling is shown within the dashed boundary. The sampling points are labeled $1,2, \cdots, 13$, and are denoted by circles containing a cross. The line 5-9 of the overlay is aligned with the jet maximum wind direction of the radiometric base map $(1: 10,000,000)$. The MRIR analysis shown is that for channel 1 . 


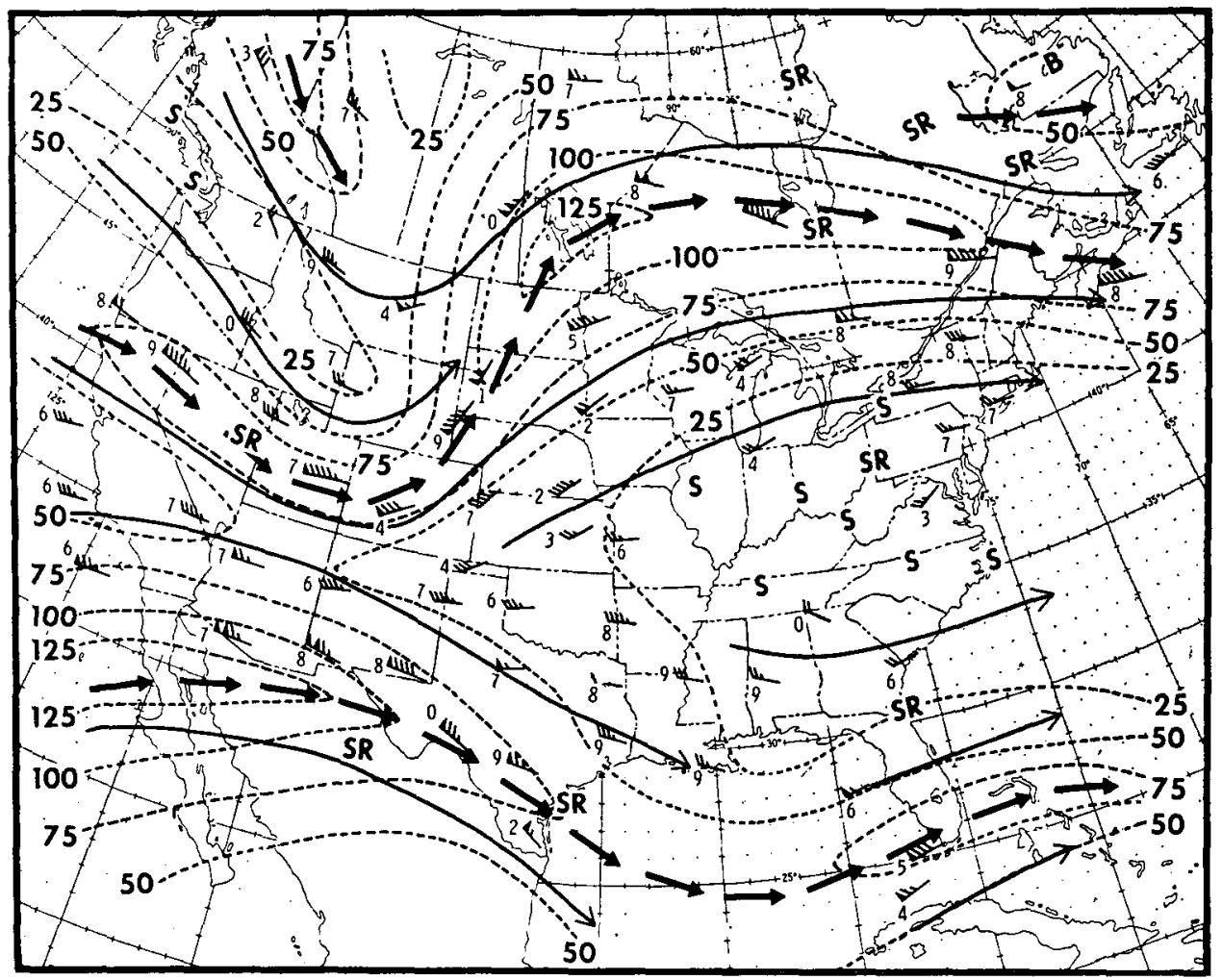

FIG. 2. The NMC maximum wind analysis for 1200 GMT 5 June 1966. The symbol SR indicates that the run terminated before the target reached the level of the maximum wind. The symbol $S$ indicates areas of maximum winds with speeds $<20 \mathrm{kt}$.

allow the determination of the jet maximum wind speed $\left(V_{\text {max }}\right)$ and the lateral wind shear $(\Delta V)$ measured normal to the jet maximum wind direction.

\section{Data sources}

\section{a. Maximum zind analysis data}

As has already been noted, a decision was made, for purposes of stratification, to limit this analysis to subtropical jet streams occurring over or near the continental United States in which the direction of flow was southwesterly. For further selection of cases in which the jet maximum could be located and its speed determined, the maximum wind analyses (MWA) prepared by the National Meteorological Center (NMC) during the Nimbus II MRIR period were used. A good example of such a chart is shown in Fig. 2. No jet maximum was chosen in any instance that was within $5^{\circ}$ longitude of either the western or eastern edges of the area illustrated in Fig. 2.

It was found useful to make systematic reference to the concurrent NMC wind shear analysis (WSA) in combination with the MWA chart for the purpose of establishing the final location and resultant magnitude of $V_{\max }$. As an example, the jet wind maximum in Fig. 2 was designated to be $125 \mathrm{kt}$ in magnitude and located midway between Tucson and EI Paso on the subtropical jet axis shown on the MWA where there was a definitive local maximum of mean vertical shear in excess of $6 \mathrm{kt}$ $(1000 \mathrm{ft})^{-1}$. If further question remained as to the location of the jet wind speed maximum, reference was made additionally to the jet maximum locations indicated on the concurrent 200 -mb analysis also prepared by NMC. Using these jet-maximum analysis procedures for each case, an estimate of the expected rms errors in location, direction and speed are $1^{\circ}$ latitude, $10^{\circ}$ azimuth and $10 \mathrm{kt}$, respectively. While the speed error estimate is open to some question, the location and direction errors are not likely to be greater than postulated. The care taken in the use of the three separate NMC analyses mentioned above would tend to confirm this statement.

A further useful tool was available as a check on the location of each subtropical jet axis. This additional data source consisted of the pictorial multi-spectral documentation prepared in the Nimbus II Medium Resolution Infrared Pictorial Data Catalog, Vols. I and II (1967). For many of the jet cases studied there was found to be a long plume of cirrus and/or water vapor rich atmosphere equatorward of the jet axis and parallel to the jet. This feature was particularly noticeable in the photo-imagery of the radiances observed in channel 1 (6.4-6.9 $\mu$; see Fig. 3). The cirrus plume in Fig. 3 is 


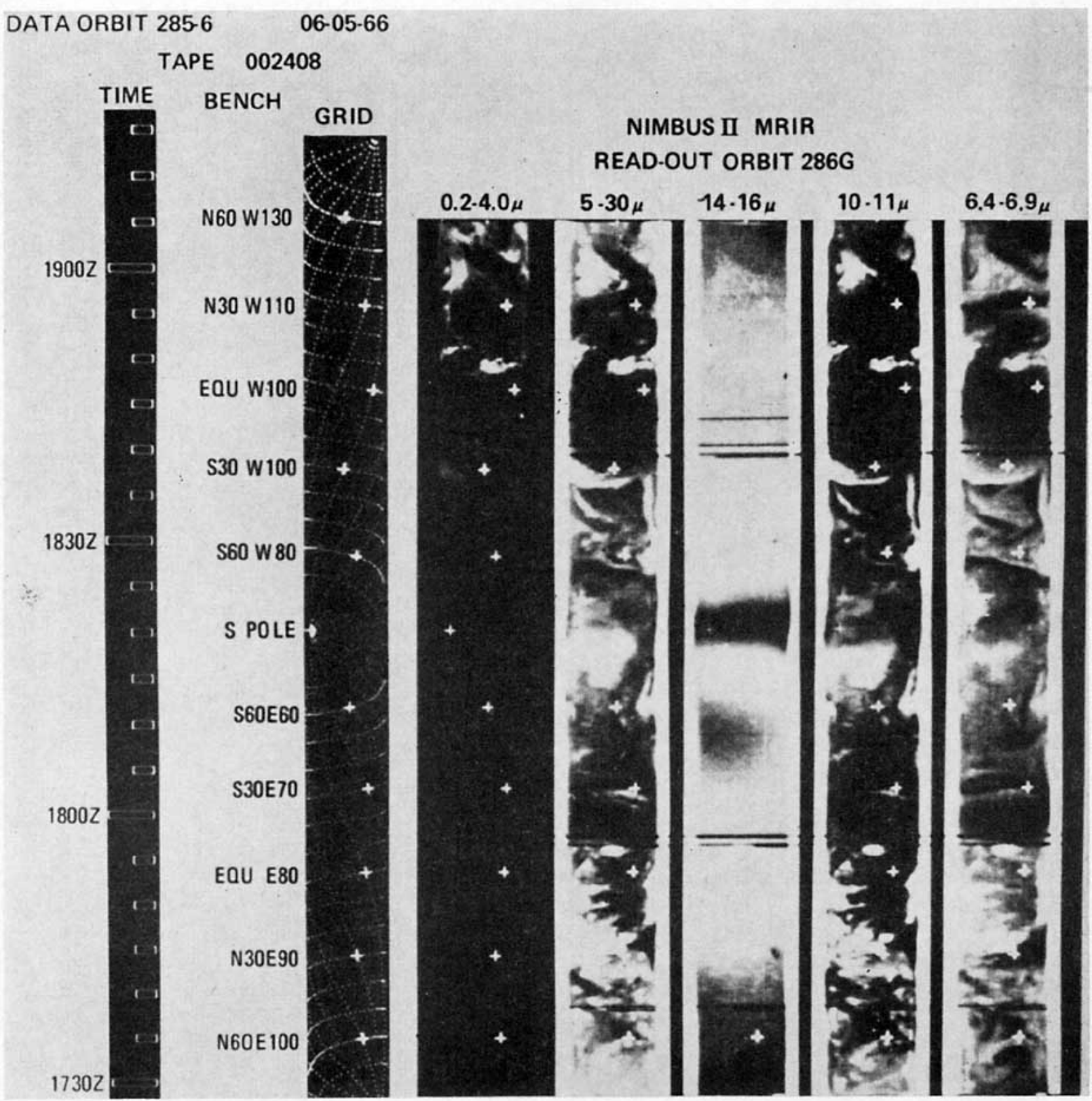

FIG. 3. The MRIR multispectral pictorial display based upon data orbit 286 . Note especially the area near $30 \mathrm{~N}$, close to 1850 GMT 5 June 1966.

recognizable to a lesser extent in channel $4(5-30 \mu)$, and in channel $2(10-11 \mu)$. The patterns in the water vapor channel (as exemplified in Fig. 3) bear a remarkable resemblance to the jet-stream cirrus patterns reported by Kadlec (1964) in his studies of jet-stream cloudiness from jet aircraft. A consistent cross check of all the NMC data sources noted above with the MRIR pictorial data was maintained throughout the study, introducing a fourth analysis procedure for determining southwesterly jet locations. However, while this latter tool was a valuable adjunct, only the digitized gridprint values of equivalent blackbody temperature $\left(T_{B B}\right)$ were used in the statistical analyses to be described.
Since the rawinsonde reports after smoothing are subject to randomly distributed errors (Reiter, 1963; Klein, 1968), the exact rms speed error will not, in general, obscure coherent $T_{B B}$ pattern-analyses relative to the jet, provided the indicated quality control of the rms errors of location and azimuth are maintained.

In addition to the maximum wind speed, the lateral wind shear $\Delta V$ was measured across each jet maximum transverse to the jet wind direction. This parameter was defined as

$$
\Delta V=\left(V_{\max }-V_{\tilde{j} n}\right)+\left(V_{\max }-V_{\tilde{j} s}\right),
$$

where $V_{5 n}$ is the speed indicated on the MWA at a point 
TABLE 1. Total sample of jet maxima which fulfilled the selection criteria (see text). The group of 30 cases in the left half (sub-sample 1) was used as the dependent sample for the regression statistics of Section 4 . Sub-sample 2 was used for the independent verification.

\begin{tabular}{|c|c|c|c|c|c|c|c|c|c|}
\hline $\begin{array}{l}\text { Date } \\
(1966)\end{array}$ & $\begin{array}{l}\text { Map } \\
\text { time } \\
(\mathrm{GMT})\end{array}$ & $\begin{array}{c}\text { Location of } \\
\text { jet maxima } \\
\text { (N lat. } / W \text { long.) }\end{array}$ & $\begin{array}{l}\text { Wind } \\
\text { direction/ } \\
\text { speed (kt) }\end{array}$ & $\begin{array}{c}\text { Wind shear } \\
{\left[\mathrm{kt}\left(10^{\circ} \text { lat. }\right)^{-1}\right]}\end{array}$ & $\begin{array}{l}\text { Date } \\
(1966)\end{array}$ & $\begin{array}{c}\text { Map } \\
\text { time } \\
(\mathrm{GMT})\end{array}$ & $\begin{array}{c}\text { Location of } \\
\text { jet maxima } \\
\text { (N lat./W long.) }\end{array}$ & $\begin{array}{l}\text { Wind } \\
\text { direction/ } \\
\text { speed }(k t)\end{array}$ & $\begin{array}{l}\text { Wind shear } \\
{\left[\mathrm{kt}\left(10^{\circ} \text { lat. }\right)^{-1}\right]}\end{array}$ \\
\hline & & Sub-sample 1 & & & & & Sub-sample 2 & & \\
\hline 20 May & 0000 & $30 / 103$ & $260 / 120$ & 130 & $20 \mathrm{May}$ & 1200 & $34 / 091$ & $270 / 105$ & 40 \\
\hline 21 May & 0000 & $30 / 103$ & $260 / 110$ & 150 & $21 \mathrm{May}$ & 1200 & $30 / 105$ & $260 / 80$ & 75 \\
\hline 22 May & 1200 & $33 / 107$ & $270 / 110$ & 100 & 22 May & 0000 & $30 / 109$ & $260 / 110$ & 70 \\
\hline $24 \mathrm{May}$ & 0000 & $32 / 110$ & $260 / 120$ & 145 & 25 May & 1200 & $32 / 114$ & $250 / 105$ & 140 \\
\hline $27 \mathrm{May}$ & 0000 & $27 / 101$ & $270 / 105$ & 80 & $28 \mathrm{May}$ & 0000 & $26 / 097$ & $270 / 80$ & 80 \\
\hline 30 May & 1200 & $36 / 116$ & $210 / 110$ & 160 & 31 May & 1200 & $32 / 116$ & $230 / 135$ & 130 \\
\hline 1 June & 1200 & $32 / 115$ & $220 / 140$ & 140 & 1 June & 0000 & $34 / 112$ & $260 / 120$ & 100 \\
\hline 2 June & 1200 & $33 / 114$ & $240 / 120$ & 100 & 2 June & 0000 & $32 / 112$ & $250 / 110$ & 70 \\
\hline 5 June & 1200 & $30 / 109$ & $260 / 130$ & 145 & 5 June & 1200 & $26 / 080$ & $250 / 80$ & 100 \\
\hline 6 June & 0000 & $39 / 104$ & $260 / 105$ & 120 & 7 June & 0000 & $38 / 111$ & $260 / 105$ & 105 \\
\hline 10 June & 1200 & $39 / 101$ & $240 / 80$ & 75 & 11 June & 1200 & $31 / 103$ & $230 / 95$ & 115 \\
\hline 12 June & 1200 & $33 / 100$ & $240 / 80$ & 80 & 13 June & 0000 & $32 / 100$ & $240 / 95$ & 140 \\
\hline 14 June & 0000 & $33 / 098$ & $260 / 80$ & 35 & 15 June & 0000 & $33 / 091$ & $260 / 80$ & 40 \\
\hline 16 June & 0000 & $31 / 100$ & $260 / 80$ & 75 & 17 June & 0000 & $31 / 096$ & $260 / 85$ & 100 \\
\hline 18 June & 0000 & $32 / 116$ & $240 / 90$ & 90 & 19 June & 0000 & $33 / 111$ & $250 / 85$ & 125 \\
\hline 27 June & 0000 & $36 / 113$ & $220 / 80$ & 100 & 26 June & 0000 & $35 / 103$ & $260 / 60$ & 50 \\
\hline 28 June & 1200 & $32 / 116$ & $210 / 75$ & 95 & 28 June & 1200 & $28 / 080$ & $240 / 60$ & 70 \\
\hline 29 June & 0000 & $39 / 109$ & $230 / 80$ & 100 & 30 June & 0000 & $30 / 081$ & $230 / 80$ & 100 \\
\hline 29 June & 1200 & $39 / 111$ & $240 / 75$ & 75 & 30 June & 1200 & $30 / 080$ & $230 / 80$ & 110 \\
\hline 30 June & 1200 & $35 / 114$ & $210 / 95$ & 110 & 2 July & 1200 & $37 / 116$ & $230 / 130$ & 115 \\
\hline 2 July & 1200 & $31 / 081$ & $230 / 80$ & 100 & 3 July & 0000 & $42 / 110$ & $230 / 120$ & 140 \\
\hline $3 \mathrm{July}$ & 0000 & $31 / 083$ & $240 / 80$ & 120 & $3 \mathrm{July}$ & 1200 & $38 / 115$ & $220 / 105$ & 85 \\
\hline 4 July & 0000 & $43 / 112$ & $230 / 105$ & 90 & 4 July & 1200 & $39 / 115$ & $220 / 105$ & 130 \\
\hline 5 July & 0000 & $43 / 108$ & $230 / 100$ & 140 & $6 \mathrm{July}$ & 0000 & $37 / 116$ & $240 / 80$ & 95 \\
\hline 7 July & 0000 & $42 / 107$ & $260 / 105$ & 130 & 8 July & 1200 & $36 / 116$ & $220 / 90$ & 100 \\
\hline 9 July & 1200 & $39 / 115$ & $210 / 140$ & 170 & $15 \mathrm{July}$ & 0000 & $36 / 117$ & $220 / 85$ & 100 \\
\hline 15 July & 1200 & $37 / 120$ & $220 / 100$ & 85 & 16 July & 0000 & $39 / 120$ & $210 / 110$ & 90 \\
\hline 16 July & 1200 & $40 / 118$ & $210 / 105$ & 120 & $21 \mathrm{July}$ & 1200 & $45 / 111$ & $230 / 105$ & 120 \\
\hline 22 July & 0000 & $47 / 102$ & $240 / 95$ & 110 & 23 July & 0000 & $46 / 103$ & $260 / 110$ & 95 \\
\hline 25 July & 1200 & $43 / 109$ & $250 / 105$ & 90 & $26 \mathrm{July}$ & 0000 & $46 / 116$ & $240 / 130$ & 155 \\
\hline
\end{tabular}

$5^{\circ}$ latitude along the positive transverse axis shown in Fig. 1, and $V_{5 s}$ is an analogous measurement taken at a point $5^{\circ}$ latitude transverse to the jet axis in the opposite direction. The shear $\Delta V$ is subject to considerably greater uncertainty than $V_{\max }$ since wind speed estimates at three points, rather than at a single point, are involved.

\section{b. Radiometric data}

The radiometric data used in this study were obtained in the form of multi-resolution Mercator grid print maps having $1.25^{\circ}$ of longitude per mesh interval. The data for these maps came from the Nimbus II meteorological radiation tapes on file at the Goddard Space Flight Center of the National Aeronautics and Space Administration. Orbits were selected for each jet case that would provide composited radiometric data coverage at each of the 13 grid points indicated in Fig. 1. Using this criterion, a final selection of jet stream cases was made from the relatively large number of jets which could be selected from the MWA, as already described. A substantial number had to be rejected because the Nimbus II Data Catalog (1966) indicated a lack of MRIR coverage over the grid shown in Fig. 1. As a result, a great deal of scrutiny was involved in acquiring 60 cases where radiometric fields provided "synoptic" coverage for the jets selected up to this point. The 60 cases finally selected are listed in Table 1.
Since the MWA charts are drawn at 0000 and 1200 GMT, daily "synoptic" radiometric coverage consisted of composited MRIR non-void fields occurring within 5 or $7 \mathrm{hr}$ on either side in time of the jet maximum case being considered. If both the "before" and "after" MRIR fields had a data gap over the gridded area around a jet maximum, the case was rejected. In general, for the cases selected (Table 1), it was possible to obtain non-void composited MRIR data over the grid consisting of two orbital swaths both in the periods prior to and after the jet wind analysis under consideration. The composited MRIR radiation fields (represented on the multi-resolution Mercator maps by equivalent blackbody temperatures) were analyzed in considerable detail for each case selected so that the data could be carefully interpolated at each of the 13 grid points lying on an acetate overlay (within the dashed boundary in Fig. 1), the tangential axis of which was aligned with the jet wind direction.

The radiation data compositing procedure described above resulted in smoothed radiometric fields nearly synoptic with 0000 and $1200 \mathrm{GMT}$ wind analyses. As a result, a nighttime orbit was always involved, and the solar reflectance channel was not used at all. The 14-16 $\mu$ data were not used because relatively small populations composited at individual points on the grid print maps were not large enough to overcome the noise in the basic data. This situation could have been 
TABLE 2. Sixty-case sample means of equivalent blackbody temperature $\bar{T}_{B B}(j)$ of the 13 grid points in channels 1,4 and 2 , and the corresponding pressure-equivalents $\bar{P}_{s}(j)$ in the $U . S$. Standard Atmosphere. Standard deviations $\sigma_{T}(j)$ for each grid point-mean temperature and its pressure-equivalent $\sigma_{P_{s}}(j)$ are also given. The sample means of $V_{\max }$ and $\Delta V$ are included in the bottom section of the table.

\begin{tabular}{|c|c|c|c|c|c|}
\hline Channel & $\begin{array}{l}\text { Grid } \\
\text { point } j\end{array}$ & $\begin{array}{c}\bar{T}_{B B}(j) \\
\left({ }^{\circ} \mathbf{K}\right)\end{array}$ & $\begin{array}{c}\sigma_{T}(j) \\
\left({ }^{\circ} \mathrm{K}\right)\end{array}$ & $\begin{array}{c}\bar{P}_{s}(j) \\
(\mathrm{mb})\end{array}$ & $\begin{array}{c}\sigma_{P_{8}}(j) \\
(\mathrm{mb})\end{array}$ \\
\hline 1 & $\begin{array}{r}1 \\
2 \\
3 \\
4 \\
5 \\
6 \\
7 \\
8 \\
9 \\
10 \\
11 \\
12 \\
13\end{array}$ & $\begin{array}{l}236.767 \\
239.333 \\
238.317 \\
238.400 \\
244.550 \\
243.217 \\
240.900 \\
239.683 \\
238.050 \\
240.667 \\
239.767 \\
238.617 \\
236.933\end{array}$ & $\begin{array}{l}5.685 \\
5.939 \\
6.320 \\
5.603 \\
5.688 \\
5.624 \\
5.993 \\
5.315 \\
4.806 \\
4.576 \\
4.626 \\
3.445 \\
3.635\end{array}$ & $\begin{array}{l}360.912 \\
381.956 \\
373.505 \\
374.189 \\
427.799 \\
415.676 \\
395.282 \\
384.897 \\
371.312 \\
393.271 \\
385.604 \\
375.985 \\
362.345\end{array}$ & $\begin{array}{l}45.568 \\
49.834 \\
52.073 \\
46.230 \\
52.316 \\
50.542 \\
51.692 \\
44.883 \\
39.420 \\
39.321 \\
39.119 \\
28.535 \\
29.227\end{array}$ \\
\hline 4 & $\begin{array}{r}1 \\
2 \\
3 \\
4 \\
5 \\
6 \\
7 \\
8 \\
9 \\
10 \\
11 \\
12 \\
13\end{array}$ & $\begin{array}{l}262.967 \\
265.916 \\
264.483 \\
265.517 \\
268.767 \\
269.017 \\
267.166 \\
265.267 \\
262.017 \\
267.483 \\
266.050 \\
265.383 \\
262.250\end{array}$ & $\begin{array}{r}12.004 \\
9.869 \\
12.051 \\
9.596 \\
7.280 \\
6.726 \\
11.108 \\
9.667 \\
9.864 \\
7.391 \\
9.358 \\
7.921 \\
8.280\end{array}$ & $\begin{array}{l}624.566 \\
664.463 \\
645.783 \\
653.164 \\
702.695 \\
706.133 \\
680.985 \\
655.909 \\
614.764 \\
685.232 \\
666.148 \\
657.414 \\
617.644\end{array}$ & $\begin{array}{r}149.870 \\
129.643 \\
154.713 \\
124.135 \\
100.063 \\
92.828 \\
148.868 \\
125.691 \\
121.686 \\
99.564 \\
123.204 \\
103.162 \\
102.541\end{array}$ \\
\hline 2 & $\begin{array}{r}1 \\
2 \\
3 \\
4 \\
5 \\
6 \\
7 \\
8 \\
9 \\
10 \\
11 \\
12 \\
13\end{array}$ & $\begin{array}{l}282.067 \\
284.583 \\
284.350 \\
285.017 \\
285.500 \\
287.250 \\
286.300 \\
285.067 \\
279.983 \\
285.450 \\
285.050 \\
284.817 \\
279.616\end{array}$ & $\begin{array}{l}16.671 \\
13.379 \\
16.706 \\
12.747 \\
11.519 \\
10.089 \\
14.797 \\
12.879 \\
13.767 \\
10.777 \\
12.163 \\
11.383 \\
12.010\end{array}$ & $\begin{array}{l}905.762 \\
949.044 \\
944.971 \\
956.677 \\
965.227 \\
995.591 \\
979.527 \\
957.560 \\
871.132 \\
964.340 \\
957.260 \\
953.154 \\
865.151\end{array}$ & $\begin{array}{l}248.288 \\
212.310 \\
257.688 \\
204.589 \\
187.954 \\
170.649 \\
238.525 \\
206.662 \\
202.895 \\
176.687 \\
196.166 \\
184.001 \\
178.355\end{array}$ \\
\hline \multicolumn{2}{|c|}{$\begin{array}{c}\text { Predictand } \\
V_{\max x} \\
\Delta V\end{array}$} & \multicolumn{2}{|c|}{$\begin{array}{l}\text { Mean } \\
67 \mathrm{kt} \\
83 \mathrm{kt}\left(10^{\circ} \text { lat. }\right)^{-1}\end{array}$} & \multicolumn{2}{|c|}{$\begin{array}{l}\text { Standard deviation } \\
19.064 \mathrm{kt} \\
29.950 \mathrm{kt}\left(10^{\circ} \text { lat. }\right)^{-1}\end{array}$} \\
\hline
\end{tabular}

partially remedied by the water vapor cloud contamination removal procedures suggested by Warnecke and McCulloch (1968) or by Woolf and Smith (1970). However, the basic hypothesis invoked here involved inferring tropospheric baroclinicity as it could be detected by channels whose maximum response occurred in the troposphere. This limits the consideration to channels 1,4 and 2 .

The equivalent blackbody temperatures $\left[T_{B B}(j)\right.$; $j=1,2, \ldots 13]$ for each of these three channels at the thirteen points shown in Fig. 1 were determined and encoded onto IBM cards in a consistent format amenable to further analysis by computer. The statistical features of the $T_{B B}(j)$ fields at the 13 points will now be described.

\section{Pattern analysis of mean MRIR equivalent blackbody temperature fields}

\section{a. Analysis of variance of the sample means of equivalent blackbody temperature $T_{B B}$}

As an initial step, the 60 -case sample means $\bar{T}_{B B}(j)$ were computed for each grid point $j$ illustrated in Fig. 1 and for each of channels 1,4 and 2 . The pressureequivalent $\bar{P}_{s}(j)$ was also computed by determining the pressure level corresponding to the observed $T_{B B}(j)$ at each grid point. This was done by using tables of temperature vs pressure for the $U$.S. Standard Atmosphere (COESA, 1962). Table 2 lists the grid-point means of the distributions, $\bar{T}_{B B}(j)$ and $\bar{P}_{s}(j)$, as well as their standard deviation, $\sigma_{T}(j)$ and $\sigma_{P_{s}}(j)$, respectively, for each grid point. Inasmuch as the latter standard deviation extends over a considerable atmospheric depth, the implied vertical variability in the equivalent pressure level is noteworthy. Since $P_{s}$ is functionally related to the temperature in these equivalences, the major thrust of the analysis of variance will be placed upon the fields of $\bar{T}_{B B}(j)$. However, one cannot fail to observe that $\sigma_{P_{s}}(j)$ in channel 2 is of such large magnitude at every grid point as to intersect the ground level unless it receives its major contribution from levels where $P_{s}(j)$ is consistently smaller than $\bar{P}_{s}(j)$. This suggests the conclusion that the sample of $P_{s}(j)$ for channel 2 is representative of a distribution strongly skewed away from near-surface levels toward cloud-top levels whenever middle or high clouds exist within the analysis grid.

The values of $\bar{T}_{B B}(j)$ and their standard deviations have been plotted for each of the thirteen points of channels 1,4 and 2 in Fig. 4, $\bar{T}_{B B}$ isotherms having been drawn at $2 \mathrm{~K}$ intervals. The $\sigma_{T}(j)$ values are also plotted and are enclosed in parentheses. The dashed lines drawn across each grid-panel denote the median values of the standard deviation. The areas delineated by the introduction of the dashed lines afford a visual aid in separating relatively high vs low variabilities in $\bar{T}_{B B}(j)$.

It should be observed that in this study a special set of MRIR channel-radiances have been isolated that are associated with cloud and/or water vapor configurations distributed relative to jet maxima. As such, these data cannot be considered in any a priori sense as being restricted to the radiances to be expected from cloudless model atmospheres (for example, see Möller and Raschke, 1964). Therefore, when considering information from the three channels 1,4 and 2 , one has a greater expectancy of observing nonredundant data in specifying MRIR patterns relative to subtropical jet maxima, and their attendant cloud features.

A more detailed examination of Fig. 4 involves analysis of the patterns of $\vec{T}_{B B}(j)$ values over each grid array. This examination reveals a warm tongue of $\bar{T}_{B B}$ oriented generally parallel to, but slightly north of, the mean jet wind axis in each case (Figs. $4 \mathrm{a}-\mathrm{c}$ ). The central value of the warm tongue appears in the mean to have a 


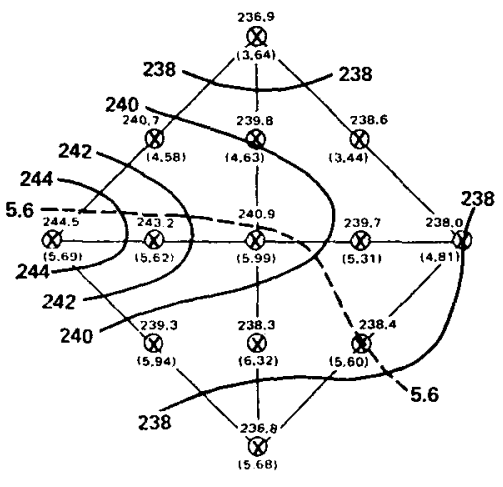

(a)

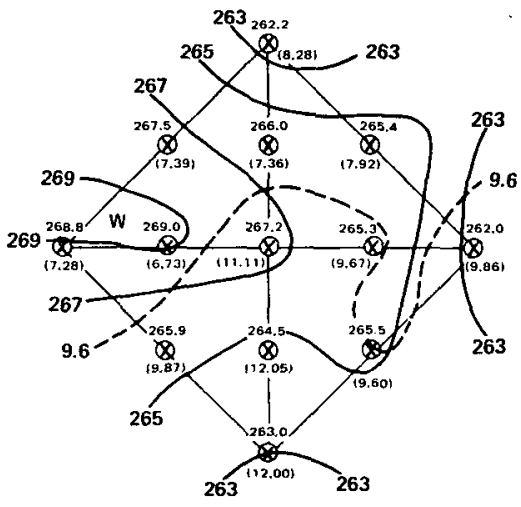

(b)

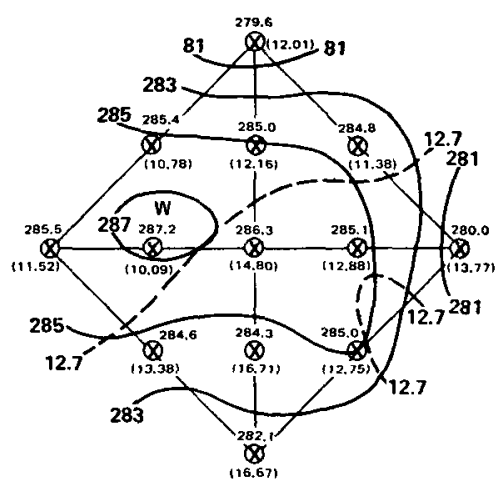

(c)

Fig. 4. Mean equivalent blackbody temperatures for each of the three channels, (a) channel 1, (b) channel 4, (c) channel 2, plotted at grid points $1, \cdots, 13$, after averaging over the sample set of 60 southwesterly subtropical jets. Isotherms are drawn as solid lines at $2 \mathrm{~K}$ intervals. Standard deviation $\sigma_{T}$ of $T_{B B}$ for each grid are displayed below each point by the number within parentheses. The dashed line(s) in each panel represents the median value of the $\sigma_{T}$ distribution.

westward tilt with increasing height. This arrangement of warm centers together with the location of cold pools near the southernmost point of the grid is consistent with statistical-physical considerations that are relevant to the southwesterly jet sample which has been collected for this study. A discussion of these considerations, as well as the cold pool to the north, will be given in Section 5. In the remainder of this section the statistical significance of the channel patterns of $\tilde{T}_{B B}(j)$ is considered. The discussion below is modeled after Crow et al. (1960, pp. 119-126), and involves inferences concerning one factor analysis of variance, and a Type I problem.

The Type I problem considered here assumes as the null hypothesis that the spatial patterns displayed in Fig. 4 are not significantly different from the grand sample means. The three 13-point mean spatial ${ }^{2}$ arrays of $T_{B B}(j, \cdot)$ will be examined and the sum-of-squares between (SSB) and the sum-of-squares within (SSW) treatments determined. The treatments discussed here are those of case-averaging at each of the 13 points over the analysis grid. The symbols SSB and SSW are defined as:

$$
\mathrm{SSB}=60 \sum_{j-1}^{13}\left[T_{B B}(j, \cdot)-\bar{T}_{B B}\right]^{2}
$$

$$
\mathrm{SSW}=\sum_{j=1}^{13} \sum_{k=1}^{60}\left[T_{B B}(j, k)-T_{B B}(j, \cdot)\right]^{2}
$$

where $T_{B B}(j, \cdot)$ is the treatment mean at grid point $j$ $(j=1,2, \cdots, 13)$ and $T_{B B}(j, k)$ the individual equivalent blackbody temperature occurring in each case at the 13 grid points $(j=1,2, \cdots 13 ; k=1,2, \cdots, 60)$. The values of $T_{B B}(j, \cdot)$ are given in Table 2 and the values of $\bar{T}_{B B}(\cdot, \cdot)$ in each channel are computed from $T_{B B}(j, \cdot)$ by averaging. The results developed for SSB and SSW are given in Table 3 along with the mean sum of squares (MSB, MSW), the degrees of freedom (DF), and the $F$ ratio, which can be expressed as

$$
F=\mathrm{MSB} / \mathrm{MSW} \text {. }
$$

In each channel, the null hypothesis is tested for possible rejection using as the critical $F$ level $\left(F_{\text {crit. }}=2.18\right)$ the $99 \%$ level with 12 and 767 degrees of freedom. It is clear that the critical $F$ level is exceeded in both channels 1 and 4, but not in channel 2. Consequently, the null hypothesis $T_{B B}(j, \cdot) T={ }_{B B}(\cdot, \cdot)$ is to be rejected in the grid arrays for channels 1 and 4 , but should not be rejected in the case of channel 2 . The statistically significant patterns in channels 1 and 4 do indeed have some physical interpretation, particularly

TABLE 3. Analysis of spatial variance for channels 1, 4 and 2, between and within grid-point means for the 13-point grid array of Fig. 1. See text for meaning of symbols.

\begin{tabular}{ccccccrr}
\hline \hline Channel & SSB & SSW & DF (SSB) & DF (SSW) & MSB & MSW & $F$ ratio \\
\hline 1 & 3717.817 & $17,961.834$ & 12 & 767 & 309.818 & 23.418 & 13.230 \\
4 & 3657.576 & $68,715.955$ & 12 & 767 & 304.798 & 89.591 & 3.402 \\
2 & 3792.204 & $132,268.22$ & 12 & 767 & 316.017 & 172.449 & 1.833 \\
\hline
\end{tabular}

2 Note the change of notation for the 60-case sample mean from $\bar{T}_{B B}(j)$ to $T_{B B}(j, \cdot)$ in accordance with the notation of Crow et al. $(1960)$. 


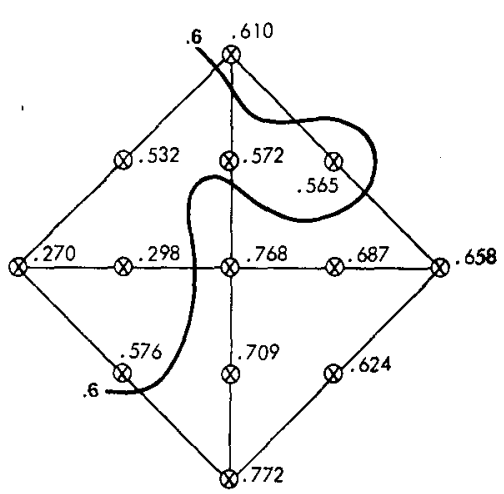

(a)

$r\left(T_{1}, T_{2}\right)$

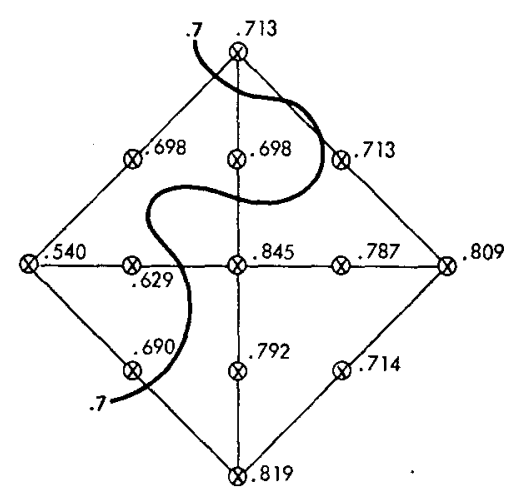

(b)

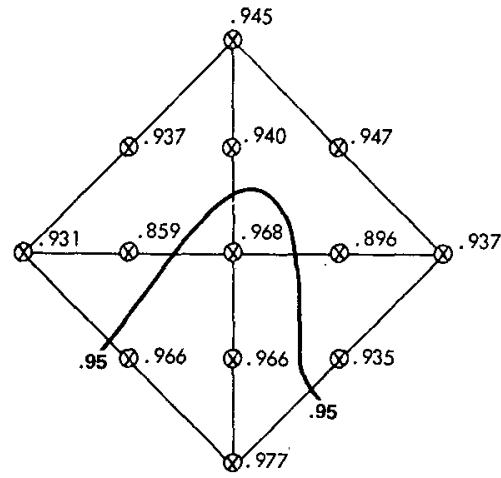

(c)

$r\left(T_{1}, T_{4}\right)$

FIG. 5. Simple correlations between pairs of channel temperatures $T_{B B}$ in channels 1,2 and 4 , at each of the 13 grid points surrounding the jet maximum. The sample size is 60 . The solid curved line denotes the median value of the correlation coefficient in each panel.

in the case of channel 1 where the $F$ ratio was quite large. More discussion of this point will be given in Section 5.

\section{b. Intra-channel correlations between equivalent black- body temperature values}

Considerable discussion has been devoted to the analysis of mean patterns of $T_{B B}$ in the three channels. It is also of interest to examine intra-channel simple correlations in order to derive further diagnostic clues which may help to characterize the MRIR radiance patterns that are observed near subtropical jet maxima. Our major effort here is directed toward deducing some of the statistical-physical implications suggested by the simple correlation coefficients of Fig. 5, and their lateral variations.

Figs. 5a-c depict in sequence the panels $r_{j}\left(T_{1}, T_{2}\right)$, $r_{j}\left(T_{1}, T_{4}\right)$ and $r_{j}\left(T_{2}, T_{4}\right)$, where $T$ is again the equivalent blackbody temperature, but the subscript $B B$ has been dropped and is replaced henceforth by numbers corresponding to the MRIR channel number. The subscript $j$ refers to the point on the analysis grid. Note that all correlation coefficients displayed are positive and are of increasing magnitude from panels $5 \mathrm{a}-\mathrm{c}$, respectively.

In Fig. 5a, values of $r_{j}\left(T_{1}, T_{2}\right)$ are generally of the order of 0.6 or higher except near the left corner of the grid. Here low correlations evidently indicate points where the warm tongue of Fig. 4a undergoes considerable variability depending upon the actual dynamical properties of the jets being sampled. In general, the overall pattern of $r_{j}\left(T_{1}, T_{4}\right)$ values bears a close resemblance to $r_{j}\left(T_{1}, T_{2}\right)$ but has a higher scale of values. The highest value which occurs in the $r_{j}\left(T_{2}, T_{4}\right)$ panel is 0.977 at point 1 . The 0.95 isopleth extends nearly parallel to the transverse axis, but is inclined slightly toward the northeast across the axis. There are, however, two areas of relatively low $r_{j}\left(T_{2}, T_{4}\right)$ values at points $j=6,8$ along the axis tangent to the jet.
The relatively small spatial variation in $r_{j}$ across panel $5 \mathrm{c}$ makes even qualitative conclusions difficult: In panels $5 a$ and $5 b$, however, in view of the fact that both channels involved are sensitive in some degree to water vapor, it appears that the more moist and/or cloudy conditions would be compatible with the resulting increase in intra-channel correlations occurring in the lower right-hand portion of the analysis grid. The lowes $t$ correlations and driest or most variable conditions tend to persist in the upper left-hand portions of Figs. 5a and $5 \mathrm{~b}$.

Since one of our objectives was to be able to discern baroclinic effects by regression methods, a new radiometric "thickness" variable $\Delta Z$ was defined in the layer $T_{15}-T_{2 j}$ for each point of the grid and for all 60 cases. This new variable $\Delta Z$ was modeled using the hypsometric formula applied with mean radiometric temperatures, and extending between the pressure-equivalent levels in each case. Thus $\Delta Z$, as modeled, assumes the familiar form

$\Delta Z=\frac{R_{d}}{g}\left[\left(\frac{T_{1}+T_{4}}{2}\right) \ln \left(\frac{P_{4}}{P_{1}}\right)+\left(\frac{T_{2}+T_{4}}{2}\right) \ln \left(\frac{P_{2}}{P_{4}}\right)\right]$.

Here $T_{1}, T_{2}$ and $T_{4}$ are the equivalent blackbody temperatures from each channel grid point and case, and $P_{1}, P_{2}$ and $P_{4}$ are the corresponding pressureequivalent levels.

If one assumes the usual equation in a polytropic atmosphere as a means of determining pressureequivalent levels, $P_{1}, P_{2}$ and $P_{4}$, it is only necessary to use the U.S. Standard Atmosphere [COESA, 1962, Eq. (I.2.10-4)], with the standard lapse rate of $0.0065 \mathrm{~K}(\mathrm{gpm})^{-1}$, to derive the relationships

$$
\left(\frac{P_{4}}{P_{1}}\right)=\left(\frac{T_{4}}{T_{1}}\right)^{5.25588},\left(\frac{P_{2}}{P_{4}}\right)=\left(\frac{T_{2}}{T_{4}}\right)^{5.25588} \text {. }
$$




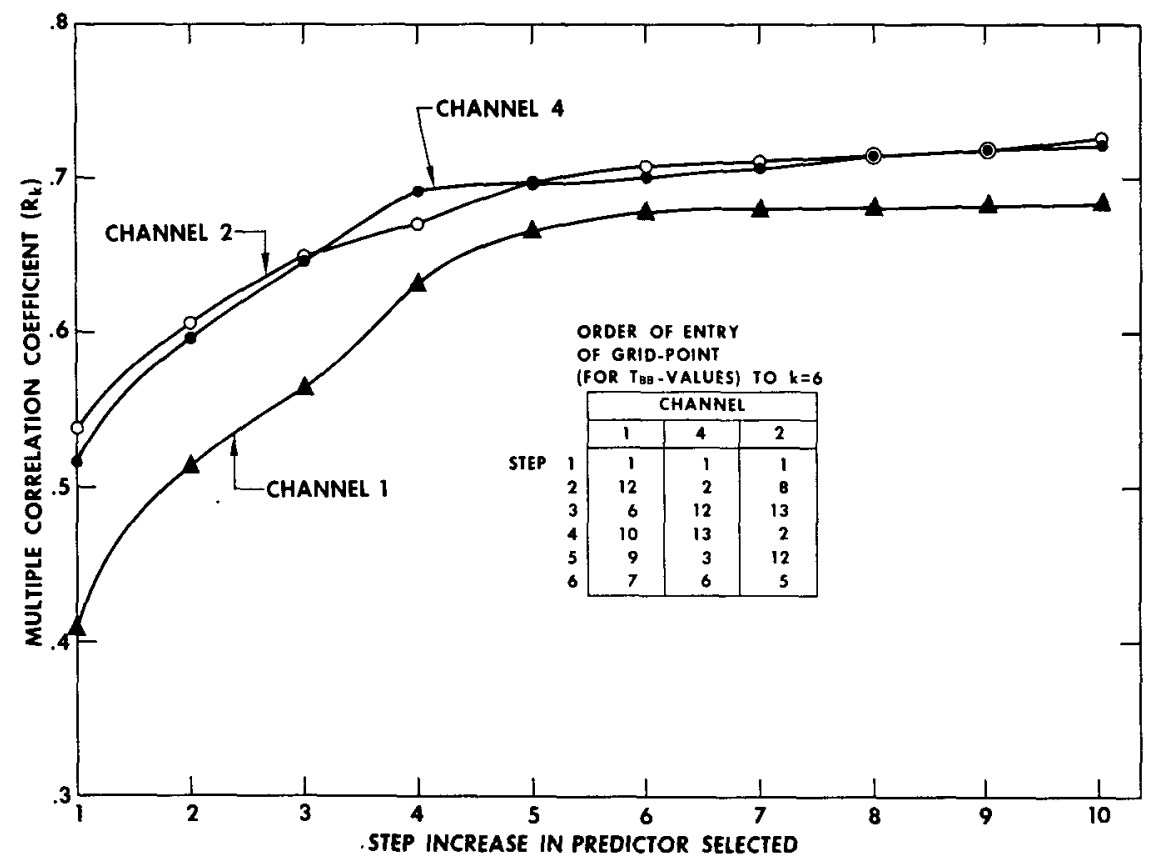

FIG. 6. Multiple correlation coefficients $R_{k}$ for $V_{\max }$ with the $k$ th step prediction equation shown using channel 1,4 and 2 grid-point temperatures $\left(T_{B B}\right)$ as separate predictors, and plotted vs $k$. Tabular inset gives the order of entry by the stepwise regression method from $k=1, \cdots, 6$ of the overlay grid-point variables selected.

The resulting expression for $\Delta Z$ is

$$
\begin{aligned}
\Delta Z=C\left[\left(T_{1}+T_{4}\right) \log _{10}\left(\frac{T_{4}}{T_{1}}\right)\right. & \\
& \left.+\left(T_{2}+T_{4}\right) \log _{10}\left(\frac{T_{2}}{T_{4}}\right)\right]=C T_{M},
\end{aligned}
$$

where $C$ of $(6)$ is defined by

$$
C=\frac{(2.30259)(5.25588)}{2 g} R_{d},
$$

and has the value $177.1089 \mathrm{gpm}\left({ }^{\circ} \mathrm{K}\right)^{-1}$ in the Standard Atmosphere. Since $C$ is a constant throughout the regression analysis, its value will be suppressed from this point on. All of the temperature sums, quotients, logarithms, etc., can be introduced as preliminary steps in the ensuing stepwise regression program. The mean temperature within the brackets in (6) may be regarded as the sum of an upper and lower layer-mean temperature over the grid for each sampling. The expressions for the upper and lower layer are, respectively:

$$
\begin{aligned}
& T_{U}=\left(T_{1}+T_{4}\right) \log \left(\frac{T_{4}}{T_{1}}\right), \\
& T_{L}=\left(T_{2}+T_{4}\right) \log \left(\frac{T_{2}}{T_{4}}\right) .
\end{aligned}
$$

One may view the application of the stepwise multiple regression procedure to the new parameter $\Delta Z$ as a means of estimating the contribution of the spatial variations of $T_{m}$ to the specification of the jet wind speed and the wind shear. A further question to be answered is whether $T_{U}$ or $T_{L}$ may be equally or more effective in the specification problem to be pursued next.

The general statistical approach to be used here, while pooling together a collection of jets in various stages of their development, has the effect of approximating the steady-state features of the jet.

\section{The regression analysis and verification}

\section{a. Preliminary examination 'of the' stepreise regression analysis}

A preliminary stepwise regression analysis, based upon the procedure of Miller (1962), was performed to specify $V_{\max }$ and $\Delta V$ from the three individual channel variable sets. In this initial step, the full sample population of 60 cases were used. The multiple correlation between $V_{\max }$ and the $k$ th $T_{B B}$ grid point selection derived using the Miller technique is shown for the three channels in Fig. 6. After the 10th step, any further increase in successive $R_{k}$ was negligibly small. However, the process of adding redundant predictors causes the standard error of estimate of $V_{\max }$ to approach its standard deviation. This is characteristic of the overspecification process described by Lorenz (1956). The first six predictors selected in the three stepwise re- 


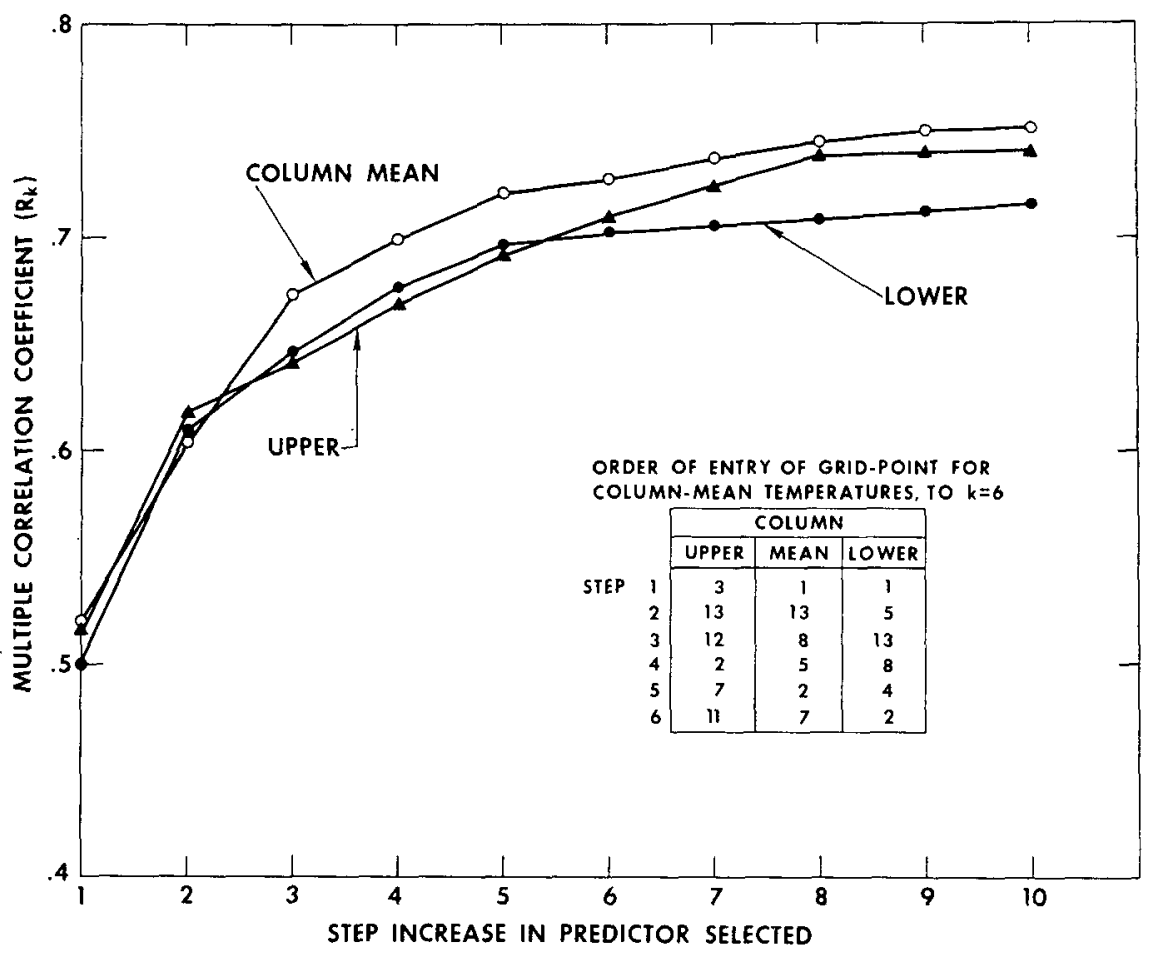

FIG. 7. Multiple correlation coefficients $R_{k}$ for $V_{\max }$ with the $k$ th step prediction equation, shown using the grid-point values of $T_{U}, T_{L}$ and $T_{M}$ of Eqs. (6) and (7) as separate predictors, and plotted vs $k$. Tabular inset gives the order of entry from $k=1, \cdots, 6$ of the grid-point variable selected in each regression.

gressions are enumerated, one set for each channel, on the right side of Fig. 6 . As it turns out, the use of prediction equations beyond the step $k=6$ is not of interest since it is found that the minimum shrinkage in $R$ (and, therefore of unexplained variance $R^{2}$ ) occurs either at step 4 or 5 in the case of $V_{\max }$. Based upon the 60 -case stepwise regressions, the multiple c srrelations at the sixth step ${ }^{3}$ for $R_{6}(V, \tilde{V})$ and for $R_{6}(\Delta V, \Delta \tilde{V})$ are listed below in Table 4 as well as the standard errors of estimate. The graph of $R(\Delta V, \Delta \tilde{V})$ is not presented here.

The standard errors in estimating $V$ are to be considered in relationship to the standard deviation of $V$, namely, $\sigma_{V}=19.0642 \mathrm{kt}$. However, the fractional explained variance is given (Crow et al., 1960) as

TABLE 4. Multiple correlation coefficient $(R)$ and standard error of estimate (S.E.) at step 6 in the stepwise multiple regression procedure for $V$ and $\Delta V$ in channels 1,4 and 2.

\begin{tabular}{ccccc}
\hline $\begin{array}{c}\text { Channel } \\
\text { no. }\end{array}$ & $R_{6}(V, \tilde{V})$ & $\begin{array}{c}\text { S.E.6, } \\
(\mathrm{kt})\end{array}$ & $R_{6}(\Delta V, \Delta \tilde{V})$ & $\begin{array}{c}\text { S.E.6 } \\
{\left[\mathrm{kt}\left(0^{\circ} \text { lat. }\right)^{-1}\right]}\end{array}$ \\
\hline 1 & 0.6778 & 14.7893 & 0.4406 & 28.3679 \\
4 & 0.7002 & 14.3660 & 0.6203 & 24.7865 \\
2 & 0.7085 & 14.1958 & 0.6060 & 25.1364 \\
\hline
\end{tabular}

"Henceforth, the subscript "max" will be deleted from $V_{\max }$ and it will be understood that $V=V_{\max }$. The superscript tilde is used to denote the statistical estimate of the variable $V$ or $\Delta V$.
$\left[1-\left(\mathrm{S} . \mathrm{E} . / \sigma_{V}\right)^{2}\right]$ and has the resultant expression

$$
\text { Fractional explained variance }=\left(\frac{n-1}{n-k-1}\right) R_{k}^{2},
$$

where $n$ is the sample size, $k$ the number of predictors selected, and $R_{k}$ the multiple correlation coefficient determined at step $k$. The values of $R_{6}(\Delta V, \Delta \widetilde{V})$ listed in Table 4 next to $R_{6}(V, \tilde{V})$ were not considered high enough to be of possible physical significance.

A similar preliminary procedure was applied to the three standard atmosphere mean-temperatures, $T_{M}, T_{U}$ and $T_{L}$, defined in Eqs. (6), (7a) and (7b), respectively. The 60-case grid samples of $T_{M}, T_{U}$ and $T_{L}$ are now treated as the analogs of $T_{1}, T_{4}$ and $T_{2}$ in determining the stepwise entry of grid point temperatures into the

TABLE 5. Multiple correlation levels $(R)$ and standard error of estimates (S.E.) at step 6 in the stepwise multiple regression procedure for $V$ and $\Delta V$ for radiometrically-defined mean temperatures $T_{U}, T_{M}, T_{L}$ of Eqs. (6) and (7).

\begin{tabular}{lccccc}
\hline $\begin{array}{c}\text { Layer- } \\
\text { mean } \\
\text { variable }\end{array}$ & \multicolumn{3}{c}{$V$} & \multicolumn{2}{c}{$\Delta V$} \\
\hline$T_{U, \text { upper }}$ & $R_{6}$ & $\begin{array}{c}\text { S.E.6 } \\
(\mathrm{kt})\end{array}$ & $R_{6}$ & {$\left[\mathrm{kt}\left(10^{\circ} \text { lat. }^{-1}\right)^{-1}\right]$} \\
$T_{M, \text { middle }}$ & 0.7098 & 14.1686 & 0.6151 & 24.9142 \\
$T_{L}$, lower & 0.7269 & 13.8130 & $\mathbf{0 . 5 5 7 7}$ & 26.2293 \\
& 0.7020 & 14.4020 & 0.6014 & 25.2459 \\
\hline
\end{tabular}


TABLE 6. Comparisons of the multiple correlation coefficients and related standard errors of estimate (kt) associated with prediction equations involving $k$ radiometric temperature predictors. Results (a) are based upon the dependent sample, while those of (b) are based upon the identical prediction equations applied to the independent sample; $S_{4}, S_{5}, S_{6}$ are based upon Eq. (9)

\begin{tabular}{|c|c|c|c|c|c|c|c|c|c|c|c|}
\hline & \multicolumn{11}{|c|}{ Predictors } \\
\hline & & & & & & $\begin{array}{c}\text { Channel } \\
1\end{array}$ & $\begin{array}{c}\text { Channel } \\
4\end{array}$ & $\begin{array}{c}\text { Channel } \\
2\end{array}$ & $\begin{array}{c}\text { Upper } \\
\text { column }\end{array}$ & $\begin{array}{l}\text { Entire } \\
\text { column }\end{array}$ & $\begin{array}{l}\text { Lower } \\
\text { column }\end{array}$ \\
\hline \multirow{9}{*}{ 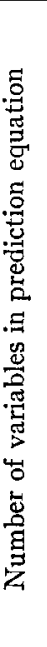 } & \multirow{3}{*}{ (a) } & \multirow{3}{*}{ 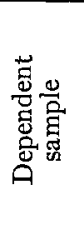 } & 4 & \multicolumn{2}{|l|}{$\begin{array}{c}R_{4} \\
\text { S.E. }\end{array}$} & $\begin{array}{r}0.6235 \\
15.9069\end{array}$ & $\begin{array}{r}0.7116 \\
14.2954\end{array}$ & $\begin{array}{r}0.6621 \\
15.2489\end{array}$ & $\begin{array}{r}0.6966 \\
14.5579\end{array}$ & $\begin{array}{r}0.6989 \\
14.5517\end{array}$ & $\begin{array}{r}0.7142 \\
14.2424\end{array}$ \\
\hline & & & 5 & \multicolumn{2}{|l|}{$\begin{array}{l}R_{\mathfrak{5}} \\
\text { S.E. }\end{array}$} & $\begin{array}{r}0.7176 \\
14.4176\end{array}$ & $\begin{array}{r}0.7352 \\
14.0769\end{array}$ & $\begin{array}{r}0.6882 \\
15.0673\end{array}$ & $\begin{array}{r}0.7276 \\
14.2461\end{array}$ & $\begin{array}{r}0.7095 \\
14.6343\end{array}$ & $\begin{array}{r}0.7301 \\
14.1899\end{array}$ \\
\hline & & & 6 & \multicolumn{2}{|l|}{$\begin{array}{c}R_{6} \\
\text { S.E. }\end{array}$} & $\begin{array}{r}0.7267 \\
14.5724\end{array}$ & $\begin{array}{r}0.7598 \\
13.7918\end{array}$ & $\begin{array}{r}0.7180 \\
14.7661\end{array}$ & $\begin{array}{r}0.7427 \\
14.2040\end{array}$ & $\begin{array}{r}0.7181 \\
14.7650\end{array}$ & $\begin{array}{r}0.7389 \\
14.2927\end{array}$ \\
\hline & & & 4 & \multicolumn{2}{|l|}{$\begin{array}{c}R_{4} \\
\text { S.E. }\end{array}$} & $\begin{array}{r}0.5146 \\
16.9847\end{array}$ & $\begin{array}{r}0.6679 \\
14.7423\end{array}$ & $\begin{array}{r}0.5986 \\
15.8677\end{array}$ & $\begin{array}{r}0.4585 \\
17.6038\end{array}$ & $\begin{array}{r}0.6406 \\
15.2098\end{array}$ & $\begin{array}{r}0.6300 \\
15.3834\end{array}$ \\
\hline & (b) & 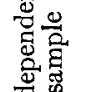 & 5 & \multicolumn{2}{|l|}{$\begin{array}{l}R_{5} \\
\text { S.E. }\end{array}$} & $\begin{array}{r}0.6051 \\
15.7709\end{array}$ & $\begin{array}{r}0.6484 \\
15.0803\end{array}$ & $\begin{array}{r}0.5889 \\
16.0099\end{array}$ & $\begin{array}{r}0.5449 \\
16.6099\end{array}$ & $\begin{array}{r}0.6554 \\
14.9607\end{array}$ & $\begin{array}{r}0.6158 \\
15.6078\end{array}$ \\
\hline & & $\varepsilon$ & 6 & \multicolumn{2}{|l|}{$\begin{array}{l}R_{6} \\
\text { S.E. }\end{array}$} & $\begin{array}{r}0.5639 \\
16.3582\end{array}$ & $\begin{array}{r}0.6460 \\
15.1206\end{array}$ & $\begin{array}{r}0.4798 \\
17.3800\end{array}$ & $\begin{array}{r}0.4798 \\
17.3793\end{array}$ & $\begin{array}{r}0.6467 \\
15.1086\end{array}$ & $\begin{array}{r}0.5997 \\
15.8513\end{array}$ \\
\hline & \multirow{3}{*}{ (c) } & \multirow{3}{*}{ 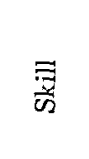 } & 4 & \multirow{3}{*}{ 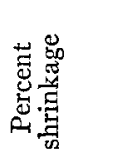 } & $S_{4}$ & 31.88 & 11.90 & 18.26 & 56.68 & 15.99 & 22.19 \\
\hline & & & 5 & & $S_{5}$ & 28.90 & 22.22 & 26.78 & 43.91 & 14.67 & 28.86 \\
\hline & & & 6 & & $S_{6}$ & 39.79 & 27.71 & 55.34 & 58.27 & 18.90 & 34.13 \\
\hline
\end{tabular}

specification equations for $V$ and $\Delta V$. The increase of the multiple correlation coefficient for $V$ with increasing step number $k$ in the resulting regression equations is shown in Fig. 7 as it pertains to the selection of predictors from the $T_{U}, T_{M}$ and $T_{L}$ grid-point arrays, respectively. The sixth-step values of $R_{k}$ depicted in Fig. 7 , with the various column-mean, grid-point temperatures as predictors, are given in Table 5. The results for $\Delta V$ are included again, but the standard errors are too large to suggest any significance.

Comparison of this tabular summary with that given in Table 4 tends to indicate a somewhat higher level of predictability for $V$ using column-mean variables $T_{U}, T_{M}$ and $T_{L}$ than is provided by the variables $T_{1}, T_{4}$ and $T_{2}$. This conclusion is tentative and an experiment has been designed to examine this question more objectively. Since the preceding tests have employed all available sample data, and no independent sample exists for verification, the presentation of specific stepwise regression equations has been reserved for the experiment to follow.

\section{b. The prediction-verification experiment}

The full data sample of $N=60$ cases was divided randomly into two equal sub-samples of 30 cases each. This was done by selecting consecutive odd and even numbered cases in the data sequence (see Table 1) as sub-samples 1 and 2, respectively. It should be recalled that the original synoptic situations were selected as objectively as possible in space and time. Therefore, the breakdown into the subdivisions just described has not reduced the objectivity employed in the initial sampling.

The stepwise multiple regression analysis was performed utilizing sub-sample 1 as the dependent data sample to develop regression equations (after Miller, 1962) from each of the six families of grid arrays designated by the notation $T_{1}, T_{2}, T_{4}, T_{U}, T_{M}, T_{L}$. It was observed that the prediction equations at step 3 were never as effective in providing explained variance either on the dependent sample nor on the independent data sample (sub-sample 2) as with $k=4$. At the other extreme, the selection of seven grid-point predictors led to increased standard errors of estimate as compared with the six-predictor case. Our tests were therefore confined to consideration of cases involving 4,5 and 6 predictor equations, each testing the six possible correlations of $V$ first with the equivalent blackbody temperatures from each of channels, 1, 4 and 2, and then with the three column-mean temperature variables $T_{U}, T_{M}$ and $T_{L}$. The resulting prediction results obtained from the dependent and independent samples are summarized in Table 6.

A criterion for ascertaining the success of a combination of $k$ predictors, termed here the "skill shrinkage" $S$, was developed. This criterion $S$ simply computes the fractional shrinkage in explained variance between the dependent and independent tests, the highest skill being associated with the smallest $S$. The fractional shrinkage of explained variance at a particular step $k$ is expressed in the form

$$
S=\frac{R_{k}^{2}-\hat{R}_{k}^{2}}{R_{k}^{2}}
$$


so that the common factor $(n-1) /(n-k-1)$ may be divided out. Here for the same prediction equation $R_{k}$ and $\hat{R}_{k}$ refer to the multiple correlation coefficient of the dependent and independent samples, respectively. Reference to Table 6 reveals that the channel 4 prediction equation with four predictors gives the best skill as defined by Eq. 9. The prediction equation is

$$
\begin{aligned}
\tilde{V}_{4}^{(4)}= & -408.40308+0.78643 T_{4}(1)+0.70356 T_{4}(2) \\
& +1.07342 T_{4}(12)-0.65427 T_{4}(13) .
\end{aligned}
$$

While Eq. (10) specifies only the jet maximum speed, and not direction, the effect of baroclinicity may be inferred, in light of Fig. 4b, by the existence of as large a difference as possible between $T_{4}(2)$ and $T_{4}(13)$. The numbers in parentheses are the points of the analysis grid selected by the stepwise regression procedure to be predictors. The estimation of $\tilde{V}$ by (10) is related to $V$ of the independent sample by the best-fit regression

$$
V=0.77716 \tilde{V}_{4}^{(4)}+21.52382,
$$

which is equivalent to the more detailed form

$$
\begin{aligned}
V=-295.87072+0.61118 T_{4}(1)+0.54678 T_{4}(2) \\
+0.98342 T_{4}(12)-0.50847 T_{4} .
\end{aligned}
$$

In (10) and (11) the superscript (4) indicates the number of predictors in both equations. Eq. (11) is subject to a coefficient of determination $R(V, \bar{V})=0.6679$ and a standard error of estimate on the independent data of $14.7423 \mathrm{kt}$.

The next best prediction equation, based upon the criterion of (9), turns out to be the column-mean temperature $T_{M}$ grid array at step 5 , in particular. Thus,

$$
\begin{aligned}
& \widetilde{V}_{M}^{(5)}=52.34735+0.64494 T_{M}(1)+0.85614 T_{M}(2) \\
& \quad+0.30653 T_{M}(4)-1.33155 T_{M}(5)+0.59781 T_{M}(10),(12)
\end{aligned}
$$

where $\tilde{V}_{M}^{(5)}$ exhibits just slightly more shrinkage upon application to the independent data-sample. The bestfit relationship between $\widetilde{V}_{M^{(5)}}$ and $\mathrm{V}$ is given by

$$
V=0.59970 \tilde{V}_{M}^{(5)}+37.7000 \text {. }
$$

The shrinkage between the dependent and independent sample trials using Eq. (12) is $14.67 \%$ and only $11.90 \%$ using (10). While all the other independent tests exhibiting minimum shrinkage are statistically significant using the $F$ ratio with 5 and 24 degrees of freedom at the $95 \%$ confidence level, $F_{\text {crit. }}=2.57$, they do not equal the verification performance of the equation pairs just discussed. For example, in the case of channel 1 prediction-verification at step 5 , the shrinkage is $28.90 \%$, whereas for channel 2 at step 4 , the corresponding shrinkage is $18.26 \%$.

The fact that channel 1 did not give better results than channel 4 is due primarily to the smaller range of the $T_{1}$ variables over the channel 1 grid as compared to that of channel-4. Since the ratios of the extreme ranges observed in channels 1 and 4 in any particular case seldom exceeded 0.4 , errors in recorded $T_{B B}$ values in channel 1 act as a larger noise source. Similar remarks apply to the comparison of verifications for channel 1 relative to channel 2 .

It appears significant that channel 4 and the columnmean "channel" represented by the variable $T_{M}$ resemble one another in the stability of their verifications. This result lends support to the earlier hypothesis that channel 4 approximates a tropospheric column-mean temperature in defining areas of strong vertical wind shear.

With regard to the specifications of $\Delta V$ by the various channels, and the subsequent verification, too much noise was compounded into the shears to permit useful verification. The most promising result was again afforded by channel 4 predictors at step 4 where the shrinkage was only $35.44 \%$. With all the other channels the prediction-verification process led essentially to standard errors in $\Delta V$ equal to the standard deviation of the independent sample, indicating no apparent predictive skill.

\section{Some statistical-physical conclusions regarding the southwesterly jet during the Nimbus II period}

We have found that the mean radiometric isotherm patterns at the levels of channels 1 and 4 have a consistent warm tongue lying somewhat north and west of the jet maximum. The westward tilt of the center of the warm tongue bears some resemblance to the westward tilt of a shortwave ridge in a baroclinic atmosphere. The warm tongue pattern suggests an area of descending motion to the west of the subtropical jet maximum, with a consistent tilt in the vertical from the tropopause to levels near the ground.

The coldest radiometric temperatures occur toward the extreme right transverse side of the jet, indicating vertically ascending air and a tendency for a moisturerich atmosphere to be indicated in all channel gridarrays in this location. Generally high $T_{B B}$ correlations between channels exist along a curved line extending close to grid points $1,2,7$ and 12 , and show a tendency for cloud and/or moisture-rich air to envelop the area in the neighborhood of the line passing through these points. The areas just described are essentially those described by Reiter (1963, p. 136) as being close to the centers of divergence associated with the southwest and northeast quadrants relative to the "advective jet model."

The vertical tilt of the maximum $T_{B B}$ centers (Fig. 4) and the persistence of these centers from case to case indicates the strong likelihood of a region of upper tropospheric convergence to the left and west of the jet. The mean $T_{B B}$ values presented in Fig. 4 also tend to confirm the presence of jet stream cirrus and/or water- 
vapor rich atmosphere extending not only in the SW and NE quadrants, but continuing well into the SE quadrant, generally paralleling the jet axis. This latter phenomenon is not entirely consistent with the Reiter advective model which would predict convergence in this sector, but is in agreement with time-lapse movies made from ATS-1 Lagrangian-type photographic sequences of individual subtropical jets made by Fujita, ${ }^{4}$ who has ascribed the prevalence of cirrus in the SE quadrant as being due to advection of thick cirrus, formed initially in the SW quadrant, and displaced into the SE quadrant, as long as the jet-level winds south of the core maintain a strength nearly equal to those of the jet axis. Visual reconnaissance by Kadlec (1964) indicates that wide areas of cirrus persist in the SE quadrant of the subtropical jet provided the jet stream "exhibits pronounced anticyclonic curvature," and if also the wind speeds remain in excess of $40 \mathrm{kt}$. Both sets of qualitative conditions just put forth, especially those of Fujita, indicate that while horizontal convergence of some magnitude exists in the SE quadrant, the rate at which a reversal to significant downdraft motions and ensuing cloud dissipation occurs is slow.

In most cases a polar front jet axis crossed the northern portion of the grid. The cool radiometric temperatures at the northernmost point (point 13) indicate the likelihood of an interaction between the subtropical jet and a polar jet to the north. This interaction appears to be indicative of moist updraft tropospheric motions in this intra-jet region, much like those found in the divergent zone on the right side of the subtropical jet.

While the analysis grid is large enough to allow only a semi-quantitative discussion, enough evidence is present to make inferences from the mean MRIR measurements regarding the location of the major convergent and divergent areas, as well as areas of most highly developed clouds, around the jet maximum. These inferences appear to be in agreement with recent observations of subtropical jets, where ample separation has been maintained between the polar front and southwesterly subtropical jets [Beran et al., 1968; Reiter and Whitney, 1969; Kadlec, 1964; Fujita (loc. cit.)]. It must be remembered that this sample comes from summer situations where subtropical jet stream features are not as pronounced as in the winter, and separations between polar front and subtropical jet streams are greater.

\section{Conclusions}

The objective here was to characterize southwesterly subtropical jet streams over North America during the Nimbus II (summer) period as observed in different spectral regions afforded by the MRIR capability. In particular, the differing responses attributable to the

\footnotetext{
4 Personal communication.
}

$6.3 \mu$ water vapor vibration-rotation band (sensed by channel 1), and the combined effects of this band, the water vapor rotational band $(\lambda>20 \mu)$, the $15 \mu$ band of $\mathrm{CO}_{2}$, and the water vapor window (all encompassed within channel 4) have been studied. Consistent patterns near jet maxima were observed in both these channels. This was evidenced by properties of the mean $T_{B B}$ patterns, which displayed features that could be associated with areas of convergence and divergence observed in other recent jet stream studies. The 5-30 $\mu$ channel provided the best overall statistical results in specifying the wind speed in the jet maximum and the shear across the jet.

In general, the results were encouraging enough, particularly in the specification of wind speed, to conclude that efforts along this line need to be continued using properly stratified wintertime jet stream cases. Presumably the $20-23 \mu$ channel available on the Nimbus III MRIR would lend itself to a continued effort of this sort in that it would provide information from lower layers in the troposphere that was only obtainable indirectly from the 5-30 $\mu$ channel. If possible, the $\mathrm{CO}_{2}$ channel $(15 \mu)$ should be included in further studies in order to deduce possible linkage between stratospheric and tropospheric flow patterns.

Acknowledgments. The authors wish to thank $\mathrm{Mr}$. William Bandeen for reading this manuscript and offering valuable suggestions. The careful analysis of grid print maps and extraction of data therefrom accomplished by Mr. Mark Smith is also greatly appreciated.

\section{REFERENCES}

Beran, D. W., E. S. Merritt and D. T. Chang, 1968 : Interpretation of baroclinic systems and wind fields as observed by Nimbus II MRIR. Final Rept., Contract NAS 5-10334, Allied Research Associates, Concord, Mass., 135 pp.

Committee on Extension to the Standard Atmosphere, 1962: U. S. Standard Atmosphere. Washington, D. C., Government Printing Office, $278 \mathrm{pp}$.

Crow, E. L., F. A. Davis and M. W. Maxfield, 1960: Statistics Manual. New York, Dover Publ., 288 pp.

Dixon, W. J., 1968: Biomedical Computer Programs. Los Angeles, University of California Press, $600 \mathrm{pp}$.

Johnson, H. M., 1966: Motions in the upper troposphere as revealed by satellite-observed cirrus formations. ESSA Tech. Rept. NESC-39, Washington, D. C., U. S. Dept. of Commerce, $92 \mathrm{pp}$.

Kadlec, P. W., 1964: A study of flight conditions associated with jet stream cirrus, atmospheric temperature change, and wind shear turbulence. Final Rept., U. S. Weather Bureau, Contract Cwb-10674, Eastern Air Lines, Atlanta, Ga., 45 pp.

Klein, G. L., 1968: A comparison of the wind accuracy obtainable from a standard radiosonde and a transponder radiosonde instrument research and development. Canadian Meteorological Res. Rept. No. 6, Dept. of Transport, Meteorological Branch, Canada, 47 pp.

Lorenz, E. N., 1956: Empirical orthogonal functions and statistical weather prediction. Sci. Rept. No. 1, Contract AF 19(604) 1566, Dept. of Meteorology, Massachusetts Institute of Technology, $49 \mathrm{pp}$. 
Miller, R. G., 1962 : Statistical prediction by discriminant analysis. Meteor. Monogr., 4, No. 25, 54 pp.

Möller, F., and E. Raschke, 1964: Evaluation of TIROS III radiation data. NASA Contractor Rept. CR-112, NASA Research Grant NsG-305, University of Munich, Germany, $84 \mathrm{pp}$.

Nimbus II Data Catalog, Vol. 2, 1966: National Space Science Data Center, Goddard Space Flight Center, NASA, Greenbelt, Md. 297 pp.

Nimbus II Medium Resolution Infrared Pictorial Data Catalog, Vols. I and II, 1967: National Space Science Data Center, Goddard Space Flight Center, NASA, Greenbelt, Md.

Nimbus II Users' Guide, 1966: National Space Science Data Center, Goddard Space Flight Center, NASA, Greenbelt, Md., $229 \mathrm{pp}$.
Oliver, V. J., R. K. Anderson and E. W. Ferguson, 1964: Some examples of the detection of jet streams from TIROS photographs. Mon. Wea. Rev., 92, 441-443.

Reiter, E. R., 1963: Jet Stream Meteorology. University of Chicago Press, $515 \mathrm{pp}$.

__ and Whitney, L. F., 1969: Interaction between subtropical and polar front jet stream. Mon. Wea. Rev., 97, 432-438.

Warnecke, G., and A. W. McCulloch, 1968: Stratospheric temperature patterns derived from Nimbus II measurements. Space Research VIII, Amsterdam, North-Holland Publ. Co., 1024-1032.

Whitney, L. F., Jr., A. Timchalk and T. I. Gray, Jr., 1966: On locating jet streams from TIROS photographs. Mon. Wea. Rev., 94, 127-138.

Woolf, H. M., and W. L. Smith, 1970: Synoptic applications of satellite radiometer data. Mon. Wea. Rev. (in press). 